\title{
L'Espill de Jaume Roig: una lectura mèdica
}

\author{
The Espill of Jaume Roig: a medical lectio
}

\author{
Jaume Pons Conca \\ jpic1@alu.ua.es \\ Universitat d'Alacant
}

Resumen: En moltes ocasions els estudis de l'Espill de Jaume Roig s'han centrat exclusivament en els aspectes misògins de l'obra, la qual cosa ha impedit aprofundir en altres aspectes que, en certa mesura, poden fins i tot alleugerir aquesta càrrega. És per això que ens proposem, en primer lloc, situar l'autor valencià en el nou paradigma teòric de la formació escolàstica, i, en segon lloc, comprovar en quin grau els coneixement teòrics d'aquesta formació, molt presents en l'Espill, contribueixen o no a una relectura menys connotada de l'obra.

Palabras clave: medicina medieval, literatura medieval, escolàstica, misogínia, Jaume Roig

Abstract: In many cases, studies on the Espill of Jaume Roig focused exclusively on the misogynist aspects of the work, which has prevented further other aspects that, maybe, may alleviate this burden. That is why we propose, first, to locate the Valencian author on the new theoretical paradigm of scholastic education, and secondly, check the extent to which knowledge of the theoretical training, present in the Espill: that will contribute or not to rreading the work less connoted.

Keywords: medieval medicine, medieval literature, scholastic, misogyn, Jaume Roig

\footnotetext{
* Aquest estudi ha sigut desenvolupat al si de l'Institut Superior d'Investigació Cooperativa IVITRA [ISIC-IVITRA] de la Generalitat Valenciana (Programa de la Generalitat Valenciana per a la Constitució i Acreditació d'Instituts Superiors d'Investigació Cooperativa d'Excel lència [Ref. ISIC/012/042]).
} 


\title{
1. La medicina de Roig: l'escolàstica
}

La faceta de professional de la medicina de Jaume Roig sempre és destacada en els estudis sobre l'Espill. Cal concretar, però, quina era la formació i el posicionament del valencià en un context heterogeni que propicià un confrontament entre les ensenyances cristianes, basades en l'aprenentatge universitari, $i$ les musulmanes $i$ jueves, fonamentades gairebé exclusivament en la comprovació empírica, que s'oblida d'explicar el fenomen tractat, tot $\mathrm{i}$ arribar a determinades conclusions. Aquest segon saber es va intentar regular i professionalitzar, sobretot a partir de l'aprovació dels Furs valencians atorgats per Alfons el Benigne el 1329:

\begin{abstract}
Las principales peculiaridades fueron: en primer lugar, la minuciosa y elaborada legislación que reguló el ejercicio de los profesionales sanitarios (médicos, cirujanos, barberos ${ }^{1}$ e, indirectamente, también apotecarios) [...] Todo ello configuró un modelo de control profesional a cuyo través intentaremos aclarar la medicina en la Valencia cristiana (García Ballester 2004: 81-82).
\end{abstract}

La creació i el foment d'universitats o centres d'Estudis Generals fou una eina necessària en aquest procés uniformant:

\begin{abstract}
El modelo institucional o universitario fue el sistema con el que la Europa occidental cristiana [...] pretendió solucionar el problema de la transmisión-adquisición de conocimientos médicos, dotándose para ello del monopolio de esa doble función: nadie podia aprender medicina fuera de las facultades de medicina. Aspiraron a poseer también el monopolio de la práctica médica: que nadie pudiese ejercer el oficio médico sin haber cursado estudios en las facultades de medicina (García Ballester 2001: 215).
\end{abstract}

Per a portar a terme la tasca regulatòria calia personal amb una preparació acadèmica acreditada que li permetera avaluar, mitjançant proves, el grau de coneixença real d'aquests practicants sobre la ciència mèdica. Jaume Roig va ocupar el càrrec d'examinador a València en diverses ocasions entre els anys 1434 i 1477,2 aprofitant l'ocasió que li donava la seua formació escolàstica. De fet, en l'Espill no s'està de criticar obertament la sapiència pressuposadament inferior d'aquell col lectiu divers. Roig ironitza de manera continuada contra els musulmans, les dones o els astròlegs que s'atreveixen a jugar amb la medicina:

Els insults i el càstig que rep la metgessa, ${ }^{3}$ per les seves pràctiques religioses del tot contràries a la conservació de l'herència masculina, posen en evidència la postura del metge Jaume

\footnotetext{
1 Sota la denominació de «medicina» s'han encabit creences i sabers de tot tipus. Com es comprova en la redacció del capítol «de metges» dels Furs, els barbers també s'amagaven en aquest paraigua, fins al punt que «el barber constituiría la célula básica y primaria de una organización sanitaria ya bastante compleja al comienzo de los años treinta del siglo XIV, que se mantendría por todo el período bajomedieval» (García Ballester 2004: 89).

2 Carré (1996: 13) concreta que ocupà el càrrec els anys 1434, 1436, 1440, 1450, 1463, 1466, 1468, 1474 i 1477.

3 Ella no deixa / cercar metgesses, / velles urquesses, / emprenyadores, / les banyadores, / mores madrines, / les adivines / e potecaris, / los herbolaris / e triaguers, / on que pogués / reme trobar (versos 4522-4533, segons l'edició publicada el 2006 per Antònia Carré, edició que se segueix per a l'elaboració del treball).
} 


\begin{abstract}
Roig gens favorable a l'exercici de la medicina per part de les dones [...] les dones jueves, mores i cristianes que exercien la medicina a l'edat mitjana i que s'encarregaven sobretot de l'obstetrícia, són apartades progressivament de la pràctica mèdica en implantar-se el model d'ensenyament universitari i escolàstic (Carré 2006: 656).
\end{abstract}

Però, què s'entén per medicina escolàstica? Es tracta d'una medicina interpretada ja no com a ofici, sinó com a professió. Fins aleshores, el que realment importava no era la possessió detallada del coneixement científic, sinó els efectes de l'aplicació pràctica. Així doncs, l’ofici de phisic era equiparable al d'altres gremis com ara els alfarers, en el sentit que el que interessava no era tant el procés com la bona confecció del producte, el guariment de la malaltia. Sovint el cos sanitari actuava per intuïció i per experiència, però ni coneixia ni cercava les causes de les patologies. L'escolàstica va intentar teoritzar tots aquests sabers obtinguts en l'activitat empírica, no sols en el camp de la medicina, sinó en molts altres. El metge valencià Arnau de Vilanova és un dels millors exponents d'aquest desig de racionalització:

\footnotetext{
El protagonismo de Arnau de Vilanova en ese cambio que la medicina universitaria de Montpellier experimentó con la introducción de lo que podemos llamar el «nuevo Galeno» en la rutina de los cursos universitarios. Iniciativa que quedó refrendada con la conocida Bula de Clemente V de 1309 por la que se reglamentó el curriculum médico de la Facultad de Medicina de Montpellier en torno, precisamente, al «nuevo Galeno» (García Ballester 2004: 280).
}

En definitiva, l'escolàstica es pot entendre com la voluntat d'actualitzar, cohesionar i redescobrir tot el coneixement mèdic obtingut des del sorgiment de la medicina hipocràtica, considerada com el primer model de medicina científica en occident, fins les aportacions dels teòrics medievals, passant per figures tan rellevants com Galè, compendiós dels avanços mèdics, o el filòsof Aristòtil, que també contribueix a ampliar els horitzons de la disciplina. Aquesta definició permet situar Jaume Roig, sens cap dubte, en el si de la medicina escolàstica.

\title{
2. Malalties en 1'Espill
}

\subsection{L'amor hereos}

La consideració de l'amor com una malaltia queda ben documentada, tant als tractats mèdics de l'època, com en diverses manifestacions literàries. Els primers expliquen l'aegritudo amoris, o l'amor hereos, que és el qualificatiu que fa servir Roig, «com un estat patològic psicofísic que trasbalsa tota l'activitat cognitiva i que demana una teràpia concreta per a arribar a la guarició» (Carré 1996: 33). De nou recorren a la teoria humoral hipocràtica per a justificar aquest trasbals que afecta 
exclusivament els hòmens, ja que «depèn de l'escalfor interna, i la dona és de naturalesa freda» (Carré 1996: 33) i que resulta alarmant des de diferents punts de vista:

L'amor hereos és la causa de la malenconia, de la pèrdua de tot control racional i de la follia. L'home que el pateix es torna asocial i solitari, i passeja per llocs oblidats de tothom. L'amor hereos és, doncs, una malaltia perillosa. Ho és per al metge, perquè significa la pèrdua de la salut. I ho és també per al teòleg i per al moralista, perquè implica la pèrdua de la llibertat de l'individu (Carre 1996: 33).

En l'Espill, el terme hereos apareix dues vegades, tot i que amb matisos d'interpretació diferents. La primera es troba al vers 8566: «perquè el coral / llur amorós / mal d’hereós / si el posseeix / sovent guareix» (8564-8570). La segona al 12104: «tens hereos, / bestil furia / de gran luxuria» (v. 1199211994). Carré fa notar el següent:

En el primer dels dos casos citats es posa èmfasi en la guarició del mal, la qual cosa indica que s'hi parla de l'amor des d'un punt de vista patològic, que es valora mèdicament el fenomen. En el segon cas, en canvi, la condemna es fa a partir d'argumentacions morals (Carré 1993: 34).

Peirats (2004: 84) detecta que algunes de les moltes malalties que apareixen a l'obra de Roig es podrien considerar com a símptomes de l'aegritudo amoris. Per exemple, relaciona la «frenetiquea» (v. 11.995) amb el deliri, símptoma clar de l'amor hereos. De la mateixa manera, avisa que «el color groc o citrí de la pell, és a dir, la icterícia, (v. 11.989) és un clar símptoma de l'aegritudo amoris».

D'acord amb la ciència mèdica, l'afecció descrita anteriorment altera els atributs cogitatius masculins, la qual cosa provoca que els seus posseïdors passen a valorar desmesuradament l'objecte de desig, és a dir, els teoritzadors mèdics entenen que n’hi ha una exaltació produïda per una visió distorsionada de la realitat. És per això que per a restablir l'ordre equilibrat de les quatre propietats hipocràtiques, i per tant la sanitat del pacient, argumenten que la malaltia s'ha de contrarestar amb un tractament que siga de naturalesa antagònica a les causes. Així doncs, els afectats per l'amor hereos, com si es tarcatra de qualsevol altra malaltia, s'han d'allunyar del focus d'infecció, és a dir, de les dones, no sols a un nivell físic, sinó també mental: han d'aconseguir incloure en l'imaginari particular una accepció tan negativament marcada d'elles com puguen. Aquest pensament conta amb precedents literaris. Per exemple, en els Remedia amoris d'Ovidi s'insereix el raonament que l'enamorat ha de fugir de qui li origina aqueix estat:

Sobre todo, aunque ataduras firmes te retengan, márchate lejos y proponte el emprender largos caminos. Llorarás y te vendrá a la memoria el nombre de la amada que has dejado y tu pie se detendrá muchas veces a mitad del camino. Pero cuanto menores sean las ganas de marcharte, más debes proponértelo; sé tenaz y obliga a tus pies a correr, aunque se nieguen a ello (Cristóbal López, 1989: 484). 
En la mateixa obra s'hi detallen tot un seguit de remeis que s'encaminen amb una mateixa direcció de desmitificar l'enamorada, com ara considerar com a defectes les seues qualitats (v. 322-332), demanar-li que mostre allò que no té (v. 333-341), visitar-la quan menys s'ho espere perquè no haja tingut temps per a empolainar-se (v. 342-357). Fins i tot Ovidi dóna per bona la solució de gitarse amb una altra abans que amb l'estimada, idea que reforça als versos 452-464, en què assegura que un amor antic s'oblida amb un altre de nou (398-408). També frega l'escatologia, amb la recomanació de practicar amb l'amada postures amoroses que resulten incòmodes.

A partir d'una lectura superficial de l'Espill es podria pensar que els difusors de la doctrina moral refusaven sistemàticament l'exercici sexual. Potser era així però, gràcies als avanços mèdics que Roig tan bé coneixia, devien saber que contribuiia a aconseguir una bona salut, ja que suposava l'evacuació de l'organisme del semen o matèria espermàtica, deixalla de la tercera digestió, produït pels testicles en el cas dels hòmens, i pels ovaris en el de les dones. En l'estudi dedicat a la Opera medica omnia d'Arnau de Vilanova s'avisa de la importància d'aqueixa evacuació:

\begin{abstract}
L'abstinència de la pràctica sexual constituiria un risc seriós per a la salut. Si no es pot eliminar correctament el semen generat en els òrgans sexuals, apareix un quadre clínic constituït pels següents símptomes: la pesadesa de cap, l'angoixa i la inapetència, també pot ocasionar l'extinció de desig [...] Hi ha per tant, des del punt de vista mèdic, una preocupació per mostrar amb claredat la necessitat absoluta de practicar una vida sexual activa (García Ballester i Mcvaugh 1996: 299-300).
\end{abstract}

Ara bé, també és cert que l'activitat sexual excessiva era rebutjada pels mateixos teòrics, ja que «produeix un assecament de la part davantera del cervell i perquè provoca una emissió de semen que no és apta per a l'engendrament» (Carré 1993: 37). En l'Espill s'expliquen, per boca de Salomó, les conseqüències de practicar el coit amb assiduitat:

\begin{abstract}
Si et tens per dit / ton foll delit / ab jove, fresca / muller, te cresca / e llong temps dure, / jo t'assegure / d'estrangulada / e d'ulcerada, molt prest -sens triga- / certa veixiga; / de gran ardor, / dolor, coissor / en l'orinar; / de tremolar / cap, peus e braços; / ab cuitas passos, / d'apoplexia / o litargia / ben tost morir (v. 6811-6829).
\end{abstract}

És per tot això que en delimitaven la pràctica a determinats moments i circumstàncies:

\footnotetext{
El moment més idoni per a fer l'acte sexual també apareix assenyalat en els regimina sanitatis. Els metges recomanen realitzar el coit quan es donen una sèrie de circumstàncies corporals, com són haver-se ultimat les digestions gàstrica i hepàtica i estar a la meitat ka tercera digestió; per consegüent, després de dormir. A més a més, és important que s’hagen eliminat les superfluïtats de la primera i segona digestió, i que el cos estiga temperat... (García Ballester i Mcvaugh 1996: 301-302).
} 
És curiós que en la mateixa obra en què s'enumeren els remeis per a combatre les passions amoroses, Remedia amoris, l'activitat sexual aconseguisca una millor valoració. Els metges medievals l'entenien com una necessitat fisiològica però, en obres literàries com aquesta es fa una passa més, i es considera, paradoxalment, que el sexe pot ser solució de l'aegritudo amoris:

\begin{abstract}
Esa sed en que perdido te abrasas, tienes que saciarla: consiento en ello; ya puedes beber en medio del río. Pero bebe más todavía de lo que pide tu estómago; procura que el agua que hayas bebido se desborde de tu garganta llena. [...] Busca el hastío de tu mal; también el hastío contribuye a poner fin (Cristóbal López, 1989: 499).
\end{abstract}

A banda d'aquestes solucions dràstiques, els tractats també n'oferien d'altres que, des del prisma de la medicina moderna, poden tindre més fonaments. ${ }^{4}$ Moltes apareixen en l'Espill, en un fragment del discurs de Salomó, a la segona part del llibre tercer:

\begin{abstract}
Usa lo bany, / rep cascun any / sagnies dues, / fes sovint sues / enans del past. / Per viure cast, / les disciplines / e, com te dines / pa i aigua usa, fin vi refusa / e beu vinagre. / lo menjar, magre / sols per la vida, / ab certa mida, ans poc que massa. / Carn de grassa, / llet e los ous, / potatges, brous, / lo menjar blanc / fan molta sang, / doncs molt sement / e moviment. / Llegums fumosos / són, e ventosos, / cuits i torrats; / ventosistats / dintre recluses / les cornamuses / fan fort inflar, / dreçar, sonar... (v. 10099-10128).
\end{abstract}

En primer lloc, el bany tenia una funció preventiva que es podia entendre com un substitut o un complement de l'exercici. En realitzar activitats físiques, el cos expulsava més superfluitats que en un estat de pausa, de manera que el bany es convertia en el procés més recomanable per a acabar d'eliminar les substàncies expulsades. A més a més, el bany era una marca social, i en els alts estaments socials hi havia un gust per la neteja. Això s'adverteix perfectament en la primera part del llibre segon, quan es contrasta el prestigi assolit per la primera dona del protagonista amb el d'altres personatges d'estaments socials inferiors: «si bé l'una hora / era complida, / ans que finida / fos llur banyada, / acompanyada / de fabres pardos, / ab balls, alardos, /cants e cançons, / ab molts brandons, / ella tornava» (v. 2694-2703). Carré ho explica:

\footnotetext{
El prestigi terapèutic i higiènic del bany, amb les seves variants del bany humit (fred o calent) i sec (amb vapor), fa que sigui recomanat per tots els regiments de sanitat com un mitjà de conservar la salut que pot substituir o completar l'exercici físic (Carré 2006: 636).
}

\footnotetext{
4 També està reglamentada la teràpia que cal aplicar en aquests casos: una dieta lleugera (hi ha aliments que provoquen la producció de semen i d'altres que la limiten), dormir molt i banyar-se sovint, cosa que retorna la digestió a l'estat normal. Així es recobra l'escalfor interna del cos i el bon moviment dels esperits. També es recomana distreure's, passejar amb els amics per llocs agradables, conversar, escoltar música i cants, fer una mica d'exercici i, sobretot, fer-se sagnies, perquè l'excés de sang en el cos provoca la sobreabundància de semen, i per tant, de desig sexual (Carré 1993: 35)
} 
En segon lloc, les sagnies, juntament amb les purgues -amb emètics o laxants- estaven considerats els mètodes més efectius i freqüents per a evacuar aquestes mateixes substàncies nocives que podien produir un desequilibri humoral en l'organisme. És per això que el savi Salomó recomana fer-se sagnar dues vegades cada any. A més a més, «els règims de salut enumeren [...] les accions positives d'un altre tipus d'evacuants hemàtics artificials, ventoses, escarificacions, sangoneres i cauteris [...] i limiten la seua acció a una zona concreta» (García Ballester i Mcvaugh1996: 315).

Finalment, una tria adequada dels aliments a ingerir, contribuïa a la millora del malalt d'amor. Per regla general, s'havien d'evitar tots aquells aliments que es considerava que portaven a la luxúria. Tot i que la classificació dels aliments pot semblar costosa segons aquests paràmetres, la major part dels textos mèdics n’oferien inventaris i, fins i tot, receptes o consells per a la seua preparació.

En la literatura catalana medieval és fàcil trobar al lusions a l'amor hereos. El cas més evident és el d'Ausiàs March, que fins i tot teoritza sobre l'amor emprant els arguments mèdics provinents de l'escola hipocràtica ja descrits. Així, en la cobla quarta del poema IV, escriu: «l'enteniment a parlar no vénc tard / e planament desféu esta raó / dient que el cos, amb sa complexió, / ha tal amor com un llop o un renard». De nou, l'alteració dels humors es presenta com a causa de la malaltia amorosa, i porta els hòmens a un estat d'irracionalitat semblant al d'un animal com el llop o la rabosa.

Hi ha també una composició en què March ofereix tota una al legoria de l'amor. Es tracta del poema LXXIX en què descriu els diferents tipus de fletxes amb què dispara Amor, i els efectes que cadascuna d'aquestes, segons la seua qualitat, té sobre l'amador. La metàfora continuada rau en la comparació implícita entre les qualitats dels metalls i el grau de puresa de l'Amor: l'or és un metall únic, que es correspon amb un Amor difícil de trobar, escàs, i d'una puresa i netedat ideals. També és el més letal. L'argent, com l'amor que representa, és molt més comú , i no és tan feridor. Finalment el plom, perfectament assequible, i per tant de menys valor, descriu un amor de menor qualitat, brut, carnal i passatger, un amor rebutjable i identificable amb la passió trastornadora de l'aegritudo amoris.

\subsection{La menstruació, la lactància materna i embriologia medieval}

Una de les qüestions de la fisiologia femenina més freqüents en l'Espill és la de la menstruació, que com ja s'ha explicat, s'usava per a degradar la imatge de la dona:

La valoració tan agra d'un fenomen fisiològic natural en les dones com és la menstruació (aquí esmentada amb un eufemisme: "son ordinari”) és freqüent en els textos literaris antifeministes [...] Com a conseqüència dels prejudicis ideològics contra les dones [...] a l'edat mitjana la menstruació és vista com una font inexhaurible de malalties contagioses, sobretot per a l'home, i de malformacions congènites en els fills engendrats (Carré 2006: 631-632). 
Peirats explica el per què d'aquesta consideració tan negativa:

\begin{abstract}
La conclusió difosa àmpliament a l'edat mitjana és que totes les dones són porta del dimoni, per tal com van desfer el compromís amb Déu. Per tant, la sentència de Déu sobre llur sexe perviu en la successivitat del fet teològic. Des d'aquest sentit, la impuresa de l'estat menstrual és tòpica al Levític, des d'on es justifica la necessitat d'un ritus d'expiació de la dona davant Déu, abans d'entrar al temple (Peirats 2004: 105).
\end{abstract}

Aquesta concepció connotada de la menstruació es reflecteix en la utilització d'eufemismes. Com a mínim, se’n fan servir tres diferents. El primer, per ordre d'aparició, és «son ordinari» (v. 2381), la intencionalitat del qual ja ha quedat explicada anteriorment. El segon apareix en la primera part del llibre tercer, en què el savi Salomó, exaltant la brutalitat i la poca compassió d'unes dones cruels capaces d'executar el seu propi fill, empra el terme «flors»: «puis per les flors / de què es nodrien / dins es peixien / per los melics» (v. 8990 - 8993). Carré en dóna la justificació, reportant les paraules de Tròtula: «les dones no poden concebre sense flor, de la mateixa manera que els arbres sense flor no donen fruit» (Carré 1993: 45). Finalment, poc després, el mateix savi s’hi refereix fent ús de la paraula «magma» (v. 9683). En aquest cas, és Peirats qui aporta un matís important: «al ludeix no tant a la moralitat del mannà miraculós que plovia del cel i nodria els fidels, com al líquid volcànic que arrossega i destrueix al seu pas tot allò amb què entre en contacte» (Peirats 2004: 106). També s’hi dóna un procés metonímic pel qual la menstruació passa a denominar-se «sanch» (v. 9649).

En l'apartat anterior es destacava la voluntat de teòrics mèdics i morals de desprestigiar les dones. En l'Espill, aquesta estratègia de menyspreu aconsegueix una major intensitat en un passatge de la primera part del llibre segon, en la descripció de la primera esposa del protagonista, a qui adreça aquestes paraules:

\begin{abstract}
Si s'adormia, / tantost roncava. / Molt m'enutjava / cascuna nit. / Sovint al llit / se orinava / he fressejava. / D’altre pudia / quan li venia / son ordinari: / sens pus pensar-hi, / cames e cuixes / les calces fluixes, / tot se n'omplia; / drap si es metia, / ab tal olor / e tal color / com Déu se sap, / llançava el drap / per los racons, / davall caixons, / entre la palla. / no hi dava malla / hom si el trobava, / lla el se lleixava / on li caïa (v. 2372-2397).
\end{abstract}

L'escena, en què la sang menstrual assoleix una força imaginística notòria és, sens dubte, de les més conegudes de l'Espill però, no l'única en què es tracta d'associar el fenomen fisiològic amb la brutícia. Així, en la tercera part del llibre segon, quan la vella fingeix estar embarassada, Roig escriu els versos següents: «dix: "sent-me llassa! / Un més me passa, / ja ma camisa / de bona guisa / e prou purguí; / deu draps n’haguíl“"» (v. 4733-4738). A més a més, també compta amb alguns precedents literaris, com ara els Remedia amoris d'Ovidi, on es recull la imatge del drap brut de la sang de la menstruació. ${ }^{5}$

\footnotetext{
5 «Ille quod a Veneris rebús surgente puella / uidit in inmundo signa pudenta toro», «otro, porque, al levantarse la muchacha después del acto amoroso, vio en el lecho revuelto manchas vergonzosas» (Cristóbal López: 487).
}

SCRIPTA, Revista internacional de literatura $i$ cultura medieval i moderna, núm. 8 / desembre 2016 / pp. 78-89 
Aquesta connotació negativa no és només una simple estratègia literària adreçada a desgastar la imatge de les dones, sinó que va més enllà, i en l'imaginari col lectiu s'imposa la idea que la menstruació està relacionada amb la brutícia, i fins i tot amb malalties com la lepra, ${ }^{6}$ com Roig plasma en la primera part del llibre tercer: «per passió / e gran calor, / fan més error / a l'engendrar / sense llavar: / seran fressoses, / e fan llebroses / ses criatures» (v. 8840-8846). Segons els metges medievals, l'home que practicara el coit amb una dona infectada per la lepra i que tinguera la menstruació es podia contagiar, i si la dona quedava embarassada, el nadó, amb total certesa, seria leprós. És per això que «els moralistes i els teòlegs prohibiran, naturalment, de mantenir relacions sexuals amb la dona que té la menstruació» (Carré 2006: 642). Francesc Eiximenis, en el capítol 856 del Dotzè del crestià, «en què les dones deuen ensenyar amor a sos marits», escriu el següent:

La sisena, que la muller reta lo deute carnal al marit quant per ell ne serà requesta, bé que, si ell és apte de hoir sos conells, ella lo pot e 1 deu, quant en si és, ascientar de abstenir del dit acte per reverència de Déu en temps de festes grans o de quaresma o quant la dona ha de sa passió natural, car en aquest cas darrer cometre la obra carnal és gran pecat al marit, pus ne sia encauat per la muller (Wittlin, 1987: 420).

Aquesta idea de poca netedat de les dones apareix un altre cop, entre els versos 7760 - 7762: «són munts de fem: / si gens se muden, olen e puden». Més tard, aqueixa pudor és directament relacionada amb el període menstrual, durant el qual les dones tenen prohibida l'entrada a l'església: «mentres sanch tenen, / ni van ni vénen / a Déu pregar; al temple entrar / no els és permés, / en l'estiu més, / per tant com puden» (v. 9643-9649).

Tanmateix, de la mateixa manera que ocorria amb el coit, la menstruació és concebuda com un mecanisme de secreció de les dones i, per a explicar per què són les dones les que la tenen, reporten la teoria de les complexions: «en els homes, l'escalfor dominant és temperada per la suor; en les dones, la humitat excessiva és purgada amb la menstruació» (Carré 1993: 44). Girolamo Manfredi dóna resposta a la pregunta «per què la dona ha les mèstrues tots mesos e l'home no?» de la següent manera:

La dona és més freda de natura que l'home e de més dèbil complecció, per la qual cosa se engendra en ella molta superfluïtat, e per ço li ha dat la natura un modo e una via de purgar tal superfluïtat, e açò ha fet per via de sanch mestruosa, que se evacua per les venes que van a la mare. E açò no s'esdevé en l'ome, de més fort e calda complecció (Carré 2004: 149).

6 «La lepra (la més important de les malalties considerades de transmissió sexual pels tractats mèdics de l'època, i que l'imaginari popular vinculava amb un inextingible ardor sexual) es considera una malaltia produïda per la sang menstrual femenina» (Carré 2006: 709). 
També es considerava que la menstruació era essencial per a l'alimentació del nadó un cop concebut. Els metges, en el seu afany per racionalitzar totes les observacions empíriques, creien que la llet materna es produïa gràcies a una part de la sang menstrual, que a través d'una vena anomenada Kiveris vena, anava a parar a les glàndules mamàries, on es convertia en llet. Per això era més que recomanable no quedar embarassada mentre s'amamantava un nadó, ja que «la sang menstrual no podria assegurar l'alimentació del nadó i la d'un embrió en formació al mateix temps» (Carré 2008: 662). En l'Espill, aquesta teoria queda reflectida en la quarta part del llibre segon, quan el protagonista té un fill que la mare es nega a alletar: «no pensau bega / -dix ab grans crits- / llet dels meus pits! / Jo novençana, / no pelícana, / plaer vull prendre, / no em plau despendre, / los pits nafrar, / per al fill dar / la sang del cos» (v. 5076-5085). Més tard, hi incidirà de nou: «molt poc reposen / desparterades. / D’un mes llevades, / ja van al bany / e fan parany / per haver llissa. / Ixen a missa ab fill o filla, / com la conilla, / ab ventre gros. / Llet no n'han ros: / meten dos fills / a grans perills / abdós de mort» (v. 9034-9047).

La lactància, que acostumava a durar fins que el nadó feia dos anys, li aportava els nutrients necessaris però, a més a més, els estudiosos estaven convençuts que era mitjançant la llet com es transmetien els tarannàs d'alletadora a alletat. És per això que, en la quarta part del llibre segon s'ataca la dona del protagonista, que tot i estar «fornida / de llet tan bona» ${ }^{7}$ (v. 5056-5057), deriva aquesta responsabilitat a una dida alemanya: «Una alemanya / jo sé tendrera, / gran filanera / com les de Silla» (v. 5094-5097). Si el conjunt de qualitats del nouvingut es determinava a partir de la llet, l'aspecte físic ho feia en el moment del coit. Manfredi, reportant Aristòtil, dóna resposta a la qüestió «per què alguns infants sèmblan al pare e altres a la mare [...]?» (Carré 2004: 250). Assegura que l'aspecte físic del nadó es pot explicar de tres maneres:

\footnotetext{
La una és per alguna fortíssima constel lació que regna en aquella hora de la concepció per la mare e ni per lo pare [...] La segona causa és la fort imaginació que ha la fembra en aquell acte, per la qual se imprimeix la figura segons aquella spècia que ella ha en l'enteniment. La terça causa és una gran debilitat de la virtut informativa de la sperma de l'home, que lavors, no podent aquella virtut produir la similitut e figura del pare en la mèstrua de la fembra, per accident produeix la forma a la qual és més inclinat dit mènstruo (Carré 2004: 250).
}

En l'espill es troba, de passada, una al lusió a la segona de les causes exposades per Manfredi, en la primera part del llibre tercer: «Lleges pintures / e variades / davant posades / quan concebran / - com de Laban / a les ovelles- / o pensant elles / d'altri figura, / torben natura, / virtuts majors / manen menors, / les animals / a naturals» (v. 8849-8860).

\footnotetext{
7 Els textos mèdics descriuen les característiques de la bona llet, que ha de ser blanca i no blava com el guix i no ha de ser ni agra, ni líquida ni coagulada. Apunten que és de millor qualitat si s'ha parit un nen (no ens ha de passar per alt que la novícia tria una dida que ha parit una filla). Expliquen també com ha de ser una bona dida: ha d'haver estat ben alimentada, no ha de ser viciosa ni ha de mantenir relacions sexuals i és millor la que ja ha parit dos cops (Carré 2001: 195-196).
} 


\section{Conclusions}

El primer qualificatiu que s'acostuma a usar en referir-se en l'Espill és el de misogin, que moltes vegades impossibilita l'apreciació d'altres aspectes de l'obra, com el mèdic, que li atorguen una dimensió totalment nova. Com s'ha vist, els conceptes de misogínia, moralitat i medicina -i també el de comicitat- sovint van de la mà, de manera que un pot contribuir a desactivar l'altre. Així, per exemple, una informació que actualment podria ser interpretada com a misògina, com pot ser el fet que la menstruació siga determinant en les possibles malformacions o malalties dels futurs nadons, potser caldria interpretar-la segons les pautes mil lenàries de la medicina medieval, que descrivia uns sabers que, tot i que avui no tenen cap fonament, suposaven el coneixement científic del moment. Per tant, una lectura de l'Espill en clau mèdica, i més concretament des del prisma de la medicina medieval, converteix en bona part la significació negativa que tradicionalment han hagut d'arrossegar Roig i la seua obra en una altra de menys connotada, almenys parcialment.

El valencià no perd en cap moment l'oportunitat d'exhibir els seus coneixements, i sempre adopta una posició respecte als debats sapiencials oberts durant el període medieval. El testimoniatge que suposa l'Espill, per tant, té un valor afegit, ja que és construït per una persona formada, per un professional amb experiència pràctica i educació teòrica, i que, com no podia ser d'una altra manera, es correspon amb les descripcions oferides pels tractats. Aquesta simbiosi és productiva i remarcable, ja que no deu haver cap altra obra en què es combinen amb un nivell tan alt de naturalitat una funció estètica o literària -una trama, element oníric, utilització del vers, jocs de paraules, comparacions, hipèrboles, etc. - , amb una presentació tan exhaustiva -amb exposicions directes o amb referències implícites- dels sabers mèdics. 


\section{Bibliografia}

Carré, A. (1996) "La medicina com a rerefons cultural a l'Espill de Jaume Roig", dins Solervicens, J. (ed.) Dos assaigs sobre cultura i literatura dels segles XV i XVI, Barcelona/Vic, Departament de Filologia Catalana de la Universitat de Barcelona.

Carré, A. (ed.) (2004) Girolamo Manfredi, Quesits i perquens: regiment de sanitat $i$ tractat de fisiognomia, Barcelona, Editorial Barcino.

Carré, A.(ed.) (2006) Jaume Roig, Espill, Barcelona, Quaderns Crema.

Cristóbal López, V. (trad.) (1989) P. Ovidio Nasón, amores, arte de amar, sobre la cosmética del rostro femenino, remedios contra el amor, Madrid, editorial Gredos.

García Ballester, L. \& Mcvaugh, M. (1996) Arnaldi de Villanova opera medica omnia X.1. Regimen sanitatis ad regem aragonum, Barcelona, Publicacions i Edicions de la Universitat de Barcelona.

García Ballester, L. (2001) La búsqueda de la salud: sanadores y enfermos en la España medieval, Barcelona, Ediciones Península.

García Ballester, L. (2004) Artifex factivus sanitatis: saberes y ejercicio profesional de la medicina en la Europa pluricultural de la Baja Edad Media, Granada, Editorial Universidad de Granada.

Peirats, A. I. (2004) Una aproximació a l'Espill' de Jaume Roig, Alzira, Institut Interuniversitari de Filologia Valenciana/Bromera.

Wittlin, C. (ed.) (1987) Francesc Eiximenis, Dotzè llibre del Crestià, Barcelona, Col legi Universitari de Girona de la Universitat Autònoma de Barcelona. 